\title{
Perioperative NT-proBNP level: Potential prognostic markers in children undergoing congenital heart disease surgery
}

Jiangbo Qu, MD, PhD, ${ }^{a}$ Huiying Liang, MD, ${ }^{b}$ Na Zhou, MD, ${ }^{a}$ Lijuan Li, MD, ${ }^{a}$ Yanfei Wang, MD, PhD, ${ }^{a}$ Jianbin $\mathrm{Li}, \mathrm{MD},{ }^{\mathrm{a}}$ and Yanqin Cui, $\mathrm{MD}^{\mathrm{a}}$

\section{ABSTRACT}

Objectives: To assess the relationship between N-terminal pro-brain natriuretic peptide (NT-proBNP) levels at different time points and early outcome, and to evaluate the reliability of NT-proBNP level as a predictor of early outcome after surgery in a large series of children with congenital heart disease (CHD).

Methods: A retrospective observational study involving 363 consecutive children with CHD was used. Plasma NT-proBNP records were obtained for each patient before and 1, 12, and 36 hours after surgery. The specificity, sensitivity, and prediction value of NT-proBNP in predicting early postoperative outcomes were determined.

Results: Analyses confirmed that time-varying NT-proBNP level, particularly 1hour postoperative levels, had prognostic value on the prediction of prolonged duration of mechanical ventilation, intensive care unit (ICU) stay, and inotropic therapy. Joint modeling analyses of a linear mixed effects model for NTproBNP from before to 36 hours after surgery and generalized linear models for the duration of the mechanical ventilation, ICU stay, and inotropic therapy showed that a $1 \%$ increase in NT-proBNP was associated with $5.5 \%, 3.9 \%$, and $3.5 \%$ relative increases in expected duration of mechanical ventilation, ICU stay, and inotropic therapy, respectively; related $P$ values were $.001, .001$, and .01 , respectively.

Conclusions: After CHD surgery, the perioperative NT-proBNP levels might be powerful markers to identify subjects at higher risk for worse outcome. (J Thorac Cardiovasc Surg 2017;154:631-40)

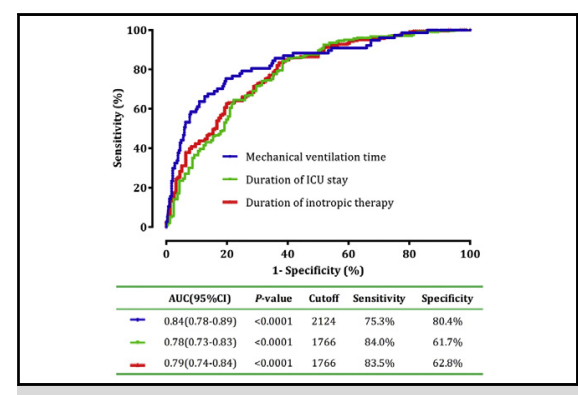

ROC curve for 1-hour NT-proBNP predicting ventilation $>48$ hours, ICU stay, and inotropic therapy $>3$ days.

\section{Central Message}

For children after CHD surgery, perioperative NT-proBNP levels might be early, accurate, and sensitive predictors of prolonged ventilation, ICU stay, and inotropic support duration.

\section{Perspective}

We found that perioperative NT-proBNP levels, particularly 1-hour postoperative levels, were correlated with duration of mechanical ventilation, ICU stay, and inotropic therapy. We used joint models to quantify the degree of the correlation between perioperative NT-proBNP level and the length of mechanical ventilation, ICU stay, and inotropic therapy. It will help clinicians to predict early outcome and plan their therapeutic protocols more quickly after surgery.

See Editorial Commentary page 641

\footnotetext{
From the ${ }^{\mathrm{a} C a r d i a c}$ Intensive Care Unit, Heart Center, and ${ }^{\mathrm{b}}$ Institute of Pediatrics, Guangzhou Women and Children's Medical Center, Guangzhou Medical University, Guangzhou, China.

J.Q. and H.L. contributed equally to the work

Received for publication April 6, 2016; revisions received Dec 16, 2016; accepted for publication Dec 29, 2016; available ahead of print March 7, 2017.

Address for reprints: Yanqin Cui, MD, Cardiac Intensive Care Unit, Heart Center, Guangzhou Women and Children's Medical Center, Guangzhou Medical University, No. 9, Rd Jinsui, Guangzhou, Guangdong, China (E-mail: 2968037903@ qq.com or litcelerychui@163.com).

$0022-5223 / \$ 36.00$

Copyright (C) 2017 by The American Association for Thoracic Surgery

http://dx.doi.org/10.1016/j.jtcvs.2016.12.056
}

Although great progress has been made, surgical intervention for the treatment of children with congenital heart disease (CHD) is still carrying significant early and late

Scanning this QR code will take you to a supplemental video for the article.

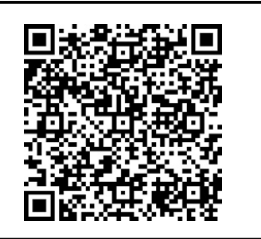




$\begin{array}{ll}\text { Abbreviations and Acronyms } \\ \text { ACC } & =\text { aorta crossclamp } \\ \text { AKI } & =\text { acute kidney injury } \\ \text { AUC } & =\text { area under the curve } \\ \text { CHD } & =\text { congenital heart disease } \\ \text { CICU } & =\text { cardiac intensive care unit } \\ \text { CPB } & =\text { cardiopulmonary bypass } \\ \text { DHCA } & =\text { deep hypothermic circulatory arrest } \\ \text { ICU } & =\text { intensive care unit } \\ \text { LCOS } & =\text { low cardiac output syndrome } \\ \text { LME } & =\text { linear mixed effects } \\ \text { LRS } & =\text { left to right shunt } \\ \text { MCMC } & =\text { Markov chain Monte Carlo } \\ \text { NT-proBNP }= & \text { N-terminal pro-brain natriuretic } \\ & \text { peptide } \\ \text { PAH } & =\text { pulmonary artery hypertension } \\ \text { RACHS-1 } & =\text { the Risk Adjustment in Congenital } \\ & \text { Heart Surgery, version 1 } \\ \text { ROC } & =\text { receiver operating characteristic } \\ \text { STAT } & =\text { Society of Thoracic Surgery- } \\ & \text { European Association for Cardio- } \\ \text { TGA } & \text { Thoracic Surgery } \\ \text { TOF } & =\text { d-transposition of the great arteries } \\ \text { UVH } & =\text { univentricular heart } \\ \text { VSD } & =\text { ventricular septal defect }\end{array}$

morbidity and mortality. Making the continued search for improved prognostic biomarkers besides commonly measured clinical and physiologic parameters is of increasing importance of children admitted to intensive care units (ICUs) after surgery for CHD. Accumulating evidence suggests that both active B-type natriuretic peptide (BNP) and inactive N-terminal pro-BNP (NT-proBNP) have been shown to have prognostic value in adults with cardiac diseases (eg, chronic congestive heart failure and acute myocardial infarction), and to predict morbidity and major adverse cardiac events after adult heart surgery.

Recently, more concerted efforts for the prognostic value of BNP/NT-proBNP after surgical intervention for CHD in pediatrics have also occurred. ${ }^{1}$ For example, Hsu and coauthors $^{2}$ found that BNP level of 1 or greater at 24 hours after cardiac surgery in neonates was correlated with poor postoperative outcome, including low cardiac output syndrome, fewer ventilator-free days, and 6-month major adverse cardiac events. Niedner et $\mathrm{al}^{3}$ reported that higher levels of early postoperative BNP were associated with longer inotropic requirement and hospitalization in children after surgery for single-ventricle CHD. Nahum and colleagues ${ }^{4}$ reported similar results in a prospective comparative study on 19 infants aged 1 to 12 months with CHD undergoing complete repair. In a prospective study on 587 children undergoing cardiac surgery, Cantinotti et $\mathrm{al}^{5}$ showed independent and incremental prognostic value of BNP in pediatric cardiac surgery, supporting its routine use in this setting.

However, current evidence is limited to BNP. ${ }^{6}$ Despite the equivalence in clinical efficacy of BNP and NT-proBNP supported by many studies, significant differences between circulatory levels has been reported for any given disease state. ${ }^{7,8}$ To our knowledge, besides a few studies focusing on the role of NT-proBNP in pediatric patients with cardiac disease, ${ }^{9}$ there are much fewer data on the prognostic value of perioperative NT-proBNP levels in children after surgical repair of structural congenital heart defects, particularly large-scale studies with high statistical power.

Therefore, the primary objectives of this article were to determine and (1) to investigate potential patterns of association between perioperative circulating NT-proBNP levels and early outcomes after repair of congenital heart defects and (2) to evaluate the reliability of NT-proBNP level as a predictor for postoperative outcomes in a large series of children undergoing cardiac surgery for CHD.

\section{PATIENTS AND METHODS \\ Subjects}

The clinical information system databases of the Guangzhou Women and Children's Medical Center were scanned for pediatric patients enrolled for cardiac surgery having CHD. Patients younger than 18 years with CHD who underwent cardiac surgery were eligible for the study. Children who had preoperative arrhythmia (potentially malignant ventricular arrhythmias and high-degree atrioventricular block), rheumatic heart disease, infective endocarditis, myocarditis, pericardial disease, renal dysfunction, or neoplasms, ${ }^{10-12}$ or who could not be separated from cardiopulmonary bypass (CPB) were excluded.

Between June and December 2014, 415 eligible consecutive patients undergoing corrective or palliative CHD surgery at the Department of Pediatric Cardiac Surgery and admitted to the Cardiac Intensive Care Unit (CICU) at the Guangzhou Women and Children's Medical Center, Guangzhou, were identified. However, to display the results in a more homogeneous population, we excluded 38 cases without CPB and 14 singleventricular cases from the final analysis according to the reviewers. Thus, results from 363 cases were presented in the current study. The institutional review board at the Guangzhou Women and Children's Medical Center reviewed and approved this study.

\section{Clinical Procedure}

The preoperative anesthesia management, surgical procedure (including sternotomy, establishing CPB, correction of cardiac defects, closure of thoracic cavity, and suturing the skin; Video 1), and subsequent CICU management followed standard institutional practices. All patients were admitted to the CICU intubated and mechanically ventilated after operation. If postoperative urine output was less than $0.5 \mathrm{~mL} / \mathrm{kg}$ per hour lasting for more than 2 to approximately 4 hours under the premise of the application of diuretics, peritoneal dialysis was adopted until the urine output was more than $2 \mathrm{~mL} / \mathrm{kg}$ per hour, blood urea nitrogen, creatinine, and electrolytes were maintained in the normal range. Termination of the surgical procedure means ending with suturing the skin.

\section{Sample and Data Collection}

Blood samples were obtained from an arterial catheter preoperatively and at 1,12 , and 36 hours after the surgical procedure at CICU according 


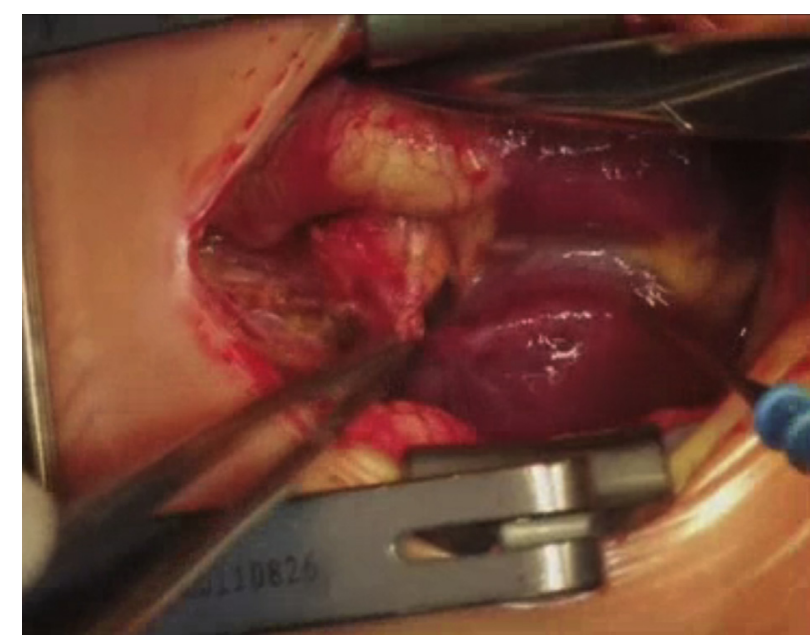

VIDEO 1. The whole procedure of the artery switch operation (ASO) for transposition of great artery (TGA) treatment. This kind of surgical procedure is one of the typical surgeries for congenital heart disease undergoing cardiopulmonary bypass. Video available at: http://www.jtcvsonline.org/ article/S0022-5223(17)30188-5/addons.

to our routine clinical protocol. The NT-proBNP levels were measured with a commercially available fluorescence immunoassay (competitive Enzyme Immuno Assay; ReLIA II, Shenzhen, China) and MultiDetection Microplate Reader (VICTOR X5; PerkinElmer, Waltham, Mass). The measurable range of NT-proBNP on this device is between 5 and approximately $35,000 \mathrm{pg} / \mathrm{mL}$ (range of normality according to age and gender).

Clinical and biochemical data were collected retrospectively from the medical records. The clinical data collected included patient demographics (age, weight, gender, main diagnosis), the Risk Adjustment in Congenital Heart Surgery, version 1 (RACHS-1) score, CPB duration, aorta cross clamp (ACC) time, and follow-up measurements after surgical procedure, including duration of mechanical ventilation, intensive care duration, inotropic drug duration, mean systemic arterial pressure, central venous pressure, serum creatinine, and urine output. The patients were divided into 3 subgroups of age according to clinically relevant data (neonates $<30$ days, infants up to 1 year, and 1 to 12 years).

\section{Data Analysis}

Categorical data were expressed as percentages and compared by using the Fisher exact test or the $\chi^{2}$ test. Continuous variables were expressed as mean and standard deviation. They were assessed for normality by the Kolmogorov-Smirnov test and compared by using the Student $t$ test or by the 1-way analysis of variance for 2- or multiple-group comparisons. Because of their abnormal distribution, NT-proBNP levels and the primary predictors (including the duration of mechanical ventilation, the length of ICU stay, and the duration of inotropic therapy) were all log-transformed for analytical purposes. Given repeated measures of NT-proBNP at fixed time points before and after surgery, we fit linear mixed effects model, combining fixed and random subject effects, for $\log$ (NT-proBNP) levels over time.

Moreover, we were also interested in the association between perioperation NT-proBNP changes over time and the duration of mechanical ventilation, ICU stay, and inotropic therapy. To analyze these data, we propose a Bayesian joint model with (1) a linear mixed effects (LME) model for the longitudinal analysis of repeated NT-proBNP measurements, and (2) a generalized linear model for the continuous primary outcomes. We used the Markov chain Monte Carlo (MCMC) technique via Gibbs sampler to estimate the unknown
TABLE 1. Clinical characteristics of cases undergoing congenital heart disease surgery

\begin{tabular}{|c|c|}
\hline Characteristics & No. \\
\hline \multicolumn{2}{|l|}{ Type of congenital heart disease } \\
\hline Ventricular septal defect & 180 \\
\hline Atrial septal defect & 38 \\
\hline Total anomalous pulmonary venous connection & 13 \\
\hline Tetralogy of Fallot & 27 \\
\hline Transposition of the great arteries & 25 \\
\hline Pulmonary atresia & 20 \\
\hline Complete atrioventricular septal defect & 15 \\
\hline Coarctation & 17 \\
\hline Double outlet right ventricle & 6 \\
\hline Interrupted aortic arch & 2 \\
\hline Pulmonary stenosis & 5 \\
\hline Other types of CHD & 15 \\
\hline \multicolumn{2}{|l|}{ RACHS- 1 score } \\
\hline $\mathrm{I} / \mathrm{II}$ & $271(74.7)$ \\
\hline III/IV & $92(25.3)$ \\
\hline $\mathrm{V} / \mathrm{VI}$ & $0(0)$ \\
\hline \multicolumn{2}{|l|}{ Demographics } \\
\hline Age, mo & $15.8 \pm 27.4$ \\
\hline Female/male & $128 / 235$ \\
\hline Body weight, $\mathrm{kg}$ & $7.4 \pm 5.7$ \\
\hline \multicolumn{2}{|l|}{ NT-proBNP level, pg/mL } \\
\hline Preoperative level & $808.6(267.0-2535.0)$ \\
\hline 1-h postoperative level & $916.9(295.9-2561.7)$ \\
\hline 12-h postoperative level & $4561.3(2760.3-8684.2)$ \\
\hline 36-h postoperative level & $3465.1(2065.6-5991.1)$ \\
\hline $\mathrm{CPB}$ time, $\min$ & $68(54-97)$ \\
\hline Aortic crossclamp time, min & $36(27-53)$ \\
\hline Mechanical ventilation, $\mathrm{h}$ & $23(9-46)$ \\
\hline Intensive care unit stay, $\mathrm{d}$ & $3(2-5)$ \\
\hline Inotropic duration, $\mathrm{d}$ & $2(1-4)$ \\
\hline
\end{tabular}

Data are expressed as $\mathrm{n}(\%)$ or median with range. $C H D$, Children with congenital heart disease; RACHS-1, risk Adjustment for Congenital Heart Surgery-1.

parameters simultaneously using publically available WinBUGS software. See Chen et $\mathrm{al}^{13}$ and Lunn et $\mathrm{al}^{14}$ for detailed discussions of the Bayesian modeling approach and the implementation of the MCMC procedures.

Receiver operating characteristic (ROC) curves were used to assess the various cutoff values of NT-proBNP to predict the need for mechanical ventilation beyond 48 hours, ICU stay beyond 3 days, and duration of inotropic therapy more than 72 hours. The areas under the curve (AUCs) for the NT-proBNP measured at different time points were compared by using De Long's method. Next, NT-proBNP levels were dichotomized to being equal to or less than the cutoff values. All tests were performed 2-tailed, with $P<.05$ considered statistically significant. Statistical analysis was performed using SPSS version 19.0 (IBM SPSS Statistics for Windows; IBM Corporation, Somers, NY) and R software (version 3.2.2).

\section{RESULTS}

The patients' clinical characteristics are listed in Table 1. There was no mortality among the enrolled patients during the study period. A total of 363 patients experienced CPB, 
excluding those diagnosed of patent ductus arteriosus, coarctation, and the single-ventricular group that accepted palliative operations. Ninety patients $(24.79 \%)$ had cyanotic CHD.

The level of postoperative NT-proBNP showed a rising trend regardless of preoperative condition. Mean levels of NT-proBNP increased significantly to the peak at 12 hours to 36 hours after $\mathrm{CPB}$ or surgical procedure.

The fixed effects estimates from the longitudinal LME model for change in $\log (\mathrm{NT}$-proBNP) are presented in Table 2. NT-proBNP levels were found to have significantly relative decreases of $76.8 \%$ and $74.1 \%$ at preoperative and 1-hour postoperative time points, but an increase of $47.7 \%$ at 12 hours after surgery, compared with that measured at 36 hours after surgery. Neonates and infants were found to have $124.8 \%$ and $76.8 \%$ higher expected NT-proBNP than the group of older children. Children who had RACHS- 1 score $\leq 2$ or with deep hypothermic circulatory arrest (DHCA) were found to have $31.6 \%$ and $56.0 \%$ lower expected NT-proBNP than the score $\geq 3$ or patients without DHCA, respectively. Postoperative creatinine level and weight were also significant predictors of NT-proBNP levels. However, no differences in expected NT-proBNP were found between male and female patients, or with the change of the length of ACC and CPB time; respective $P$ values were .16, .10, and .36.

As shown in Table 3, the results for the longitudinal submodel were consistent with the results from the separate LME analysis. The differences in magnitudes of the parameter estimates were negligible and there was no material difference in terms of statistical significance (Tables 2 and 3). Hence, in what follows, we discuss only the results for the second submodels. Most importantly, we found that a $1 \%$ increase in NT-proBNP level was associated with a relative increase of $5.5 \%$ in expected duration of the mechanical ventilation. Compared with 36-hour postoperative NT-proBNP level, 1-hour $(P=.03)$ and 12-hour postoperative NT-proBNP $(P=.01)$ were also significantly associated with the duration of mechanical ventilation.

All patients were discharged between 1 and 41 days. Time-varying NT-proBNP was associated with the prolonged ICU stay. A $1 \%$ increase in NT-proBNP was associated with a $3.9 \%$ prolonged duration of ICU stay. Patients whose RACHS- 1 score was $\leq 2$ were found to have $8.6 \%$ lower expected ICU stay than patients with a

TABLE 2. Estimates for linear mixed model of repeated NT-proBNP

\begin{tabular}{|c|c|c|c|c|c|}
\hline Variables & Estimate & SE & $95 \%$ CI & $P$ & $\mathbf{R E} \%$ \\
\hline Intercept & 8.79 & 0.30 & 8.20 to 9.38 & $<.0001 *$ & NA \\
\hline \multicolumn{6}{|l|}{ Time points } \\
\hline Before surgery & -1.46 & 0.08 & -1.62 to -1.30 & $<.0001 *$ & -76.78 \\
\hline $1 \mathrm{~h}$ after surgery & -1.35 & 0.07 & -1.49 to -1.21 & $<.0001 *$ & -74.08 \\
\hline $12 \mathrm{~h}$ after surgery & 0.39 & 0.06 & 0.27 to 0.51 & $<.0001 *$ & 47.70 \\
\hline $36 \mathrm{~h}$ after surgery & Reference & & & & \\
\hline \multicolumn{6}{|l|}{ Gender } \\
\hline Female & -0.13 & 0.09 & -0.31 to 0.05 & .16 & -12.19 \\
\hline Male & Reference & & & & \\
\hline \multicolumn{6}{|l|}{ Age } \\
\hline Neonates $(<30 \mathrm{~d})$ & 0.81 & 0.25 & 0.32 to 1.30 & $.002 *$ & 124.79 \\
\hline Infants $(<1 \mathrm{y})$ & 0.57 & 0.13 & 0.32 to 0.82 & $<.0001 *$ & 76.83 \\
\hline $1-12 y$ & Reference & & & & \\
\hline \multicolumn{6}{|l|}{ RACHS-1 } \\
\hline$\leq 2$ & -0.38 & 0.13 & -0.63 to -0.13 & $.004 *$ & -31.61 \\
\hline$\geq 3$ & Reference & & & & \\
\hline \multicolumn{6}{|l|}{ DHCA } \\
\hline No & -0.82 & 0.19 & -1.19 to -0.45 & $<.0001 *$ & -55.96 \\
\hline Yes & Reference & & & & \\
\hline \multicolumn{6}{|c|}{ Serum creatinine, $\mu \mathrm{mol} / \mathrm{L}$} \\
\hline Preoperative & -0.004 & 0.008 & -0.02 to 0.01 & .63 & -0.40 \\
\hline Postoperative & 0.03 & 0.006 & 0.02 to 0.04 & $<.0001 *$ & 3.05 \\
\hline CPB time, $\min$ & 0.003 & 0.002 & -0.001 to 0.01 & .10 & 0.30 \\
\hline ACC time, $\min$ & 0.003 & 0.003 & -0.003 to 0.01 & .36 & 0.30 \\
\hline Weight, kg & -0.08 & 0.01 & -0.10 to -0.06 & $<.0001 *$ & -7.69 \\
\hline
\end{tabular}


TABLE 3. Results for the joint modeling analysis of a linear mixed effects model for NT-proBNP from before to 36 hours after surgery and a generalized linear model for the duration of the mechanical ventilation

\begin{tabular}{|c|c|c|c|c|}
\hline Variables & Estimate $(95 \%$ CI $)$ & SE & $\boldsymbol{P}$ & $\mathbf{R E} \%$ \\
\hline \multicolumn{5}{|l|}{ The first submodel } \\
\hline Intercept & $8.85(8.44-9.26)$ & 0.21 & $<.0001 *$ & NA \\
\hline \multicolumn{5}{|l|}{ Time points } \\
\hline Before surgery & $-1.41(-1.59$ to -1.23$)$ & 0.09 & $<.0001^{*}$ & -75.59 \\
\hline $1 \mathrm{~h}$ after surgery & $-1.3(-1.48$ to -1.12$)$ & 0.09 & $<.0001 *$ & -72.75 \\
\hline $12 \mathrm{~h}$ after surgery & $0.37(0.21$ to 0.53$)$ & 0.08 & $<.0001^{*}$ & 44.77 \\
\hline $36 \mathrm{~h}$ after surgery & Reference & & & \\
\hline \multicolumn{5}{|l|}{ Gender } \\
\hline Female & $-0.12(-0.24$ to -0.002$)$ & 0.06 & .06 & -11.31 \\
\hline Male & Reference & & & \\
\hline \multicolumn{5}{|l|}{ Age } \\
\hline Neonates $(<30 \mathrm{~d})$ & $0.81(0.46$ to 1.16$)$ & 0.18 & $<.0001^{*}$ & 124.79 \\
\hline Infants $(<1 \mathrm{y})$ & $0.6(0.42$ to 0.78$)$ & 0.09 & $<.0001 *$ & 82.21 \\
\hline $1-12 y$ & Reference & & & \\
\hline \multicolumn{5}{|l|}{ RACHS-1 } \\
\hline$\leq 2$ & $-0.38(-0.56$ to -0.20$)$ & 0.09 & $<.0001 *$ & -31.61 \\
\hline$\geq 3$ & Reference & & & \\
\hline \multicolumn{5}{|l|}{ DHCA } \\
\hline No & $-0.75(-1.00$ to -0.50$)$ & 0.13 & $<.0001^{*}$ & -52.76 \\
\hline Yes & Reference & & & \\
\hline \multicolumn{5}{|c|}{ Serum creatinine, $\mu \mathrm{mol} / \mathrm{L}$} \\
\hline Preoperative & $-0.004(-0.02$ to 0.02$)$ & 0.01 & .69 & -0.40 \\
\hline Postoperative & $0.03(0.02$ to 0.04$)$ & 0.01 & $<.0001^{*}$ & 3.05 \\
\hline $\mathrm{CPB}$ time, $\min$ & $0.004(0.002$ to 0.01$)$ & 0.001 & $.002 *$ & 0.40 \\
\hline ACC time, min & $0.0003(-0.004$ to 0.004$)$ & 0.002 & .87 & 0.03 \\
\hline Weight, kg & $-0.07(-0.08$ to -0.06$)$ & 0.007 & $<.0001 *$ & -6.76 \\
\hline \multicolumn{5}{|l|}{ The second submodel } \\
\hline Log(NT-proBNP) & 0.05 (0.02 to 0.09$)$ & 0.02 & $.001 *$ & 5.51 \\
\hline \multicolumn{5}{|l|}{ Time points } \\
\hline Before surgery & $0.0004(-0.06$ to 0.06$)$ & 0.03 & .99 & 0.04 \\
\hline $1 \mathrm{~h}$ after surgery & $0.08(0.01$ to 0.16$)$ & 0.04 & $.03^{*}$ & 8.64 \\
\hline $12 \mathrm{~h}$ after surgery & $-0.25(-0.43$ to -0.07$)$ & 0.09 & $.01 *$ & -22.06 \\
\hline $36 \mathrm{~h}$ after surgery & Reference & & & \\
\hline \multicolumn{5}{|l|}{ Gender } \\
\hline Male & -0.03 ( -0.08 to 0.03$)$ & 0.03 & .37 & -2.51 \\
\hline Female & Reference & & & \\
\hline \multicolumn{5}{|l|}{ Age } \\
\hline Neonates $(<30 \mathrm{~d})$ & $0.66(-0.71$ to 2.03$)$ & 0.70 & .34 & 93.65 \\
\hline Infants $(<1 \mathrm{y})$ & $-0.31(-1.16$ to 0.54$)$ & 0.43 & .47 & -26.80 \\
\hline $1-12 y$ & Reference & & & \\
\hline \multicolumn{5}{|l|}{ RACHS-1 } \\
\hline$\leq 2$ & $-0.04(-0.15$ to 0.06$)$ & 0.05 & .41 & -4.28 \\
\hline$\geq 3$ & Reference & & & \\
\hline \multicolumn{5}{|l|}{ DHCA } \\
\hline No & $0.12(-0.02$ to 0.26$)$ & 0.07 & .08 & 12.75 \\
\hline Yes & Reference & & & \\
\hline \multicolumn{5}{|c|}{ Serum creatinine, $\mu \mathrm{mol} / \mathrm{L}$} \\
\hline Preoperative & $-8.14(-22.96$ to 6.68$)$ & 7.41 & .28 & -99.97 \\
\hline Postoperative & $-0.09(-11.42$ to 11.24$)$ & 5.66 & .99 & -8.61 \\
\hline $\mathrm{CPB}$ time, $\min$ & $0.06(-22.11$ to 22.23$)$ & 11.27 & 1.00 & 5.97 \\
\hline ACC time, $\min$ & $-4.13(-18.70$ to 10.44$)$ & 7.40 & .58 & -98.39 \\
\hline Weight, kg & $-0.34(-1.07$ to 0.38$)$ & 0.37 & .35 & -29.08 \\
\hline
\end{tabular}

$\mathrm{RE} \%$ corresponding to an estimate $\beta$, expressed as expected percentage change in NT-proBNP, calculated as (exp[ $\beta]-1) * 100 . N T$-proBNP, N-terminal pro-brain natriuretic peptide; $S E$, standard error; $C I$, confidence interval; $R E \%$, percentage relative effects; $N A$, not available; RACHS-1, Risk Adjustment for Congenital Heart Surgery-1; $D H C A$, deep hypothermic circulatory arrest; $C P B$, cardiopulmonary bypass; $A C C$, aorta cross clamp. ${ }^{*} P<.05$. 
TABLE 4. Results for the joint modeling analysis of a linear mixed effects model for NT-proBNP from before to 36 hours after surgery and a generalized linear model for the duration of intensive care unit stay

\begin{tabular}{|c|c|c|c|c|}
\hline Variables & Estimate $(95 \%$ CI $)$ & SE & $\boldsymbol{P}$ & $\mathbf{R E} \%$ \\
\hline \multicolumn{5}{|l|}{ The second submodel } \\
\hline Log(NT-proBNP) & $0.04(0.02$ to 0.06$)$ & 0.01 & $.001^{*}$ & 3.87 \\
\hline \multicolumn{5}{|l|}{ Time points } \\
\hline Before surgery & 0.004 ( -0.04 to 0.04$)$ & 0.02 & .85 & 0.37 \\
\hline $1 \mathrm{~h}$ after surgery & $0.03(-0.02$ to 0.08$)$ & 0.03 & .30 & 2.83 \\
\hline $12 \mathrm{~h}$ after surgery & $-0.15(-0.28$ to -0.02$)$ & 0.06 & $.02 *$ & -13.70 \\
\hline $36 \mathrm{~h}$ after surgery & Reference & & & \\
\hline \multicolumn{5}{|l|}{ Gender } \\
\hline Male & $0.02(-0.02$ to 0.06$)$ & 0.02 & .32 & 1.99 \\
\hline Female & Reference & & & \\
\hline \multicolumn{5}{|l|}{ Age } \\
\hline Neonates $(<30 \mathrm{~d})$ & $0.29(-0.67$ to 1.25$)$ & 0.49 & .55 & 33.77 \\
\hline Infants $(<1 \mathrm{y})$ & $-0.11(-0.70$ to 0.49$)$ & 0.30 & .72 & -10.11 \\
\hline $1-12$ y & Reference & & & \\
\hline \multicolumn{5}{|l|}{ RACHS-1 } \\
\hline$\leq 2$ & $-0.09(-0.16$ to -0.02$)$ & 0.04 & $.02 *$ & -8.63 \\
\hline$\geq 3$ & Reference & & & \\
\hline \multicolumn{5}{|l|}{ DHCA } \\
\hline No & $0.10(0.003$ to 0.19$)$ & 0.05 & $.04 *$ & 10.33 \\
\hline Yes & Reference & & & \\
\hline \multicolumn{5}{|c|}{ Serum creatinine, $\mu \mathrm{mol} / \mathrm{L}$} \\
\hline Preoperative & $-1.28(-11.97$ to 9.41$)$ & 5.34 & .81 & -72.20 \\
\hline Postoperative & $1.30(-6.87$ to 9.48$)$ & 4.09 & .75 & 266.93 \\
\hline CPB time, $\min$ & $-7.91(-23.45$ to 7.62$)$ & 7.89 & .32 & -99.96 \\
\hline ACC time, min & $1.44(-8.76$ to 11.65$)$ & 5.19 & .78 & 323.64 \\
\hline Weight, kg & $0.25(-0.26$ to 0.76$)$ & 0.26 & .33 & 28.92 \\
\hline
\end{tabular}

$\mathrm{RE} \%$ corresponding to an estimate $\beta$, expressed as expected percentage change in NT-proBNP, calculated as (exp $[\beta]-1) * 100 . N T$-proBNP, N-terminal pro-brain natriuretic peptide; $C I$, confidence interval; $S E$, standard error; $R E \%$, percentage relative effects; $R A C H S$-1, Risk Adjustment for Congenital Heart Surgery-1; DHCA, deep hypothermic circulatory arrest; $C P B$, cardiopulmonary bypass; $A C C$, aorta cross clamp. $* P<.05$.

score $\geq 3$. Patients who experienced DHCA were estimated to have a $10.3 \%$ higher expected ICU stay than patients who did not experience DHCA (Table 4).

On joint model analysis, NT-proBNP and RACHS-1 score were found to be independent predictors of prolonged duration of inotropic therapy (Table 5). Having adjusted for confounding variables, there was still a $3.5 \%$ (multivariate $P=.01$ ) increase in the likelihood of prolonged duration of inotropic therapy for each $1 \%$ increase in NT-proBNP.

On ROC curve analyses, NT-proBNP measured at 1 hour after surgery had better performance as compared with the 36-hour postoperative level in predicting longer duration of mechanical ventilation ( $>48$ hours) (AUC, 0.84 vs $0.76 ; z=2.08 ; P=.04$ ), as shown in Figures 1-4. However, no significant differences in discrimination between the perioperative NT-proBNP levels at different time points for both prolonged ICU stay ( $>3$ days) and duration of inotropic therapy (>3 days) were found. The optimal cut points for preoperative and 1-hour, 12-hour, and 36-hour postoperative NT-proBNP and the corresponding sensitivity and specificity in detecting longer duration of mechanical ventilation, ICU stay, and inotropic therapy are shown in Figure 1.

\section{DISCUSSION}

The current study suggests and expands some already present views that perioperative NT-proBNP levels in the children undergoing CHD constructive surgery are predictive of postoperative affairs (eg, the prolonged mechanical ventilation time, ICU stay, and inotropic support duration after surgery).

The prognostic values of perioperative NT-proBNP levels in the setting of cardiac surgery have been mainly determined in the adult population and to a lesser extent in pediatrics. As far as we know, this is the largest study to assess the prognostic value of NT-proBNP in unselected heterogeneously aged children undergoing cardiac surgery for CHD. Furthermore, this is also the first study reporting the prognostic utility of NT-proBNP level at as early as 1 hour after surgery in this population, suggesting an important role for its use in postoperative management.

This study also characterized the alternations of NTproBNP levels during the perioperative period of children 
TABLE 5. Results for the joint modeling analysis of a linear mixed effects model for NT-proBNP from before to 36 hours after surgery and a generalized linear model for the duration of inotropic therapy

\begin{tabular}{|c|c|c|c|c|}
\hline Variables & Estimate $(95 \%$ CI $)$ & SE & $\boldsymbol{P}$ & $\mathbf{R E} \%$ \\
\hline \multicolumn{5}{|l|}{ The second submodel } \\
\hline Log(NT-proBNP) & 0.03 (0.01 to 0.06$)$ & 0.01 & $.01^{*}$ & 3.46 \\
\hline \multicolumn{5}{|l|}{ Time points } \\
\hline Before surgery & $0.001(-0.04$ to 0.05$)$ & 0.02 & .98 & 0.07 \\
\hline $1 \mathrm{~h}$ after surgery & $0.05(-0.01$ to 0.11$)$ & 0.03 & .10 & 5.21 \\
\hline $12 \mathrm{~h}$ after surgery & $-0.17(-0.31$ to -0.02$)$ & 0.07 & $.03^{*}$ & -15.40 \\
\hline $36 \mathrm{~h}$ after surgery & Reference & & & \\
\hline \multicolumn{5}{|l|}{ Gender } \\
\hline Male & Reference & & & \\
\hline Female & $0.002(-0.04$ to 0.05$)$ & 0.02 & .92 & 0.22 \\
\hline \multicolumn{5}{|l|}{ Age } \\
\hline Neonates $(<30 \mathrm{~d})$ & $0.11(-0.99$ to 1.22$)$ & 0.56 & .84 & 12.07 \\
\hline Infants $(<1 \mathrm{y})$ & $0.01(-0.67$ to 0.69$)$ & 0.35 & .97 & 1.22 \\
\hline $1-12 y$ & Reference & & & \\
\hline \multicolumn{5}{|l|}{ RACHS-1 } \\
\hline$\leq 2$ & $-0.09(-0.17$ to -0.01$)$ & 0.04 & $.03^{*}$ & -8.60 \\
\hline$\geq 3$ & Reference & & & \\
\hline \multicolumn{5}{|l|}{ DHCA } \\
\hline No & $0.10(-0.01$ to 0.21$)$ & 0.06 & .07 & 10.74 \\
\hline Yes & Reference & & & \\
\hline \multicolumn{5}{|c|}{ Serum creatinine, $\mu \mathrm{mol} / \mathrm{L}$} \\
\hline Preoperative & $-3.52(-14.98$ to 7.94$)$ & 5.73 & .54 & -97.04 \\
\hline Postoperative & $1.06(-7.71$ to 9.82$)$ & 4.38 & .81 & 188.64 \\
\hline CPB time, $\min$ & $-1.63(-19.42$ to 16.16$)$ & 9.04 & .86 & -80.43 \\
\hline ACC time, min & $-0.64(-12.34$ to 11.05$)$ & 5.94 & .91 & -47.48 \\
\hline Weight, kg & $-0.03(-0.62$ to 0.55$)$ & 0.30 & .91 & -3.37 \\
\hline
\end{tabular}

$\mathrm{RE} \%$ corresponding to an estimate $\beta$, expressed as expected percentage change in NT-proBNP, calculated as (exp $[\beta]-1) * 100 . N T$-proBNP, N-terminal pro-brain natriuretic peptide; $C I$, confidence interval; $S E$, standard error; $R E \%$, percentage relative effects; $R A C H S$ - 1 , Risk Adjustment for Congenital Heart Surgery-1; $D H C A$, deep hypothermic circulatory arrest; $C P B$, cardiopulmonary bypass; $A C C$, aorta cross clamp. $* P<.05$.

undergoing surgical repair for CHD. Postoperative NTproBNP values begin to increase 1 hour after surgery, reaching a maximum level at 12 hours after surgery. However, Pérez-Piaya et $\mathrm{al}^{15}$ observed the NT-proBNP values start to rise 6 hours after surgery, peaking at 24 hours after the operation in a prospective study of 68 children ( $0-15$ years) submitted to open-heart surgery. The inconsistencies among studies may result from a variety of reasons; for example, different sampling time, different bypass or myocardial protecting techniques, or different postoperative medical management.

Given the difference of BNP/NT-proBNP levels in children according to age, ${ }^{9,16}$ we also evaluated the alterations in NT-proBNP levels of children and neonates over time in separate analyses. Neonates $(\mathrm{n}=30)$, however, on average show relatively lower levels at 1 hour after surgery (before surgery: $12,131 \pm 10,123 \mathrm{pg} / \mathrm{mL} \rightarrow 1$ hour after surgery: $9610 \pm 5592 \mathrm{pg} / \mathrm{mL} \rightarrow 12$ hours after surgery: $13,438 \pm 9711 \mathrm{pg} / \mathrm{mL} \rightarrow 36$ hours after surgery: $12,037 \pm 6298 \mathrm{pg} / \mathrm{mL})$. Similar results were reported by Cannesson et $\mathrm{al}^{17}$ in neonates $(\mathrm{n}=30)$ undergoing transposition of the great arteries, of which BNP level progressively declined after surgery compared with the baseline and then increased gradually over the next 24 hours. This different postsurgery pattern of BNP/NT-proBNP kinetics compared with older children may in part be contributed to the generally higher disease severity and greater operation complexity.

Among perioperative NT-proBNP values at 4 different time points (from before to 1,12 , and 36 hours after surgery), all were found to be positively correlated with duration of mechanical ventilation, ICU stay, and inotropic drug therapy. Value at 1 hour after operation had the highest prediction value (Figure 1). Thus, why are 1-hour postoperative NT-proBNP levels more strongly correlated with subsequent prognoses compared with the preoperative value? It may be that BNP/NT-proBNP values after cardiac surgery reflect the comprehensive cardio-renal function and the extension of surgical response. ${ }^{18}$ The significant prognostic value of BNP level occurring as early as 8 to 12 hours after operation has been reported, ${ }^{4,19,20}$ but it is noteworthy that many adverse events occurred within the first 12 hours. ${ }^{21}$ Thus, BNP/NT-proBNP levels measured either before or at 12 hours after surgery will prevent prognostic utility among these patients. To our delight, the 1-hour NTproBNP level after surgery (Figure 1) was also predictive 


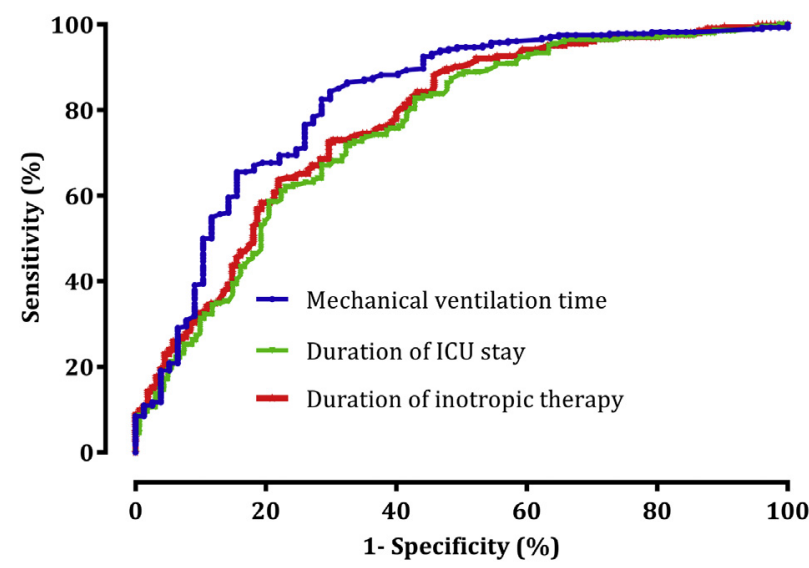

\begin{tabular}{cccccc}
\hline & AUC(95\%CI) & $\boldsymbol{P}$-value & Cutoff & Sensitivity & Specificity \\
\hline$\rightarrow$ & $0.82(0.76-0.88)$ & $<0.0001$ & 2454 & $85.8 \%$ & $68.8 \%$ \\
$\rightarrow$ & $0.75(0.70-0.80)$ & $<0.0001$ & 1763 & $57.1 \%$ & $82.8 \%$ \\
$-\quad 0.77(0.72-0.82)$ & $<0.0001$ & 920 & $70.3 \%$ & $72.5 \%$ \\
\hline
\end{tabular}

FIGURE 1. Receiver operating characteristic curve for N-terminal probrain natriuretic peptide level before surgery predicting the need for mechanical ventilation beyond 48 hours, intensive care unit (ICU) stay and duration of inotropic therapy beyond 3 days. $A U C$, Area under the curve; $C I$, confidence interval.

of prolonged mechanical ventilation, ICU stay, and inotropic support treatment; that is, this earlier time point might also have clinical utility within the first 12 to 48 hours postoperatively. ${ }^{20}$

Furthermore, it is well known that circulating levels of BNP/NT-proBNP in patients can be affected by various extracardiac conditions. Thus, it needs to be highlighted that postoperative NT-proBNP levels and their subsequent prognostic value may be affected by several factors. First, given different NT-proBNP response at 1-hour after surgery between neonates and older children, the predictive values of this index have been evaluated in separate analysis. In neonates, results showed that with the exception of the relationship between preoperative levels and ICU stay, no significant association between perioperative NT-proBNP levels and mechanical ventilation, ICU stay, or inotropic support treatment duration were found. Similarly, a study about BNP by Hsu et $\mathrm{al}^{2}$ showed that both preoperative and postoperative (2,12, and 24 hours after cardiac surgery) levels in 36 neonates had no significant prognostic value.

In addition, changing BNP/NT-proBNP levels were proportionally influenced by the CPB ${ }^{22,23}$ Besides the current study, we also evaluated it in a homogeneous cohort without $\mathrm{CPB}(\mathrm{n}=38)$. It is confirmed that results of patients without $\mathrm{CPB}$ were consistent and in line with the results of cases with $\mathrm{CPB}$.

Another major factor is with regard to the assessment of renal function, which could confound the blood NTproBNP levels. $^{24,25}$ In our study, children were excluded

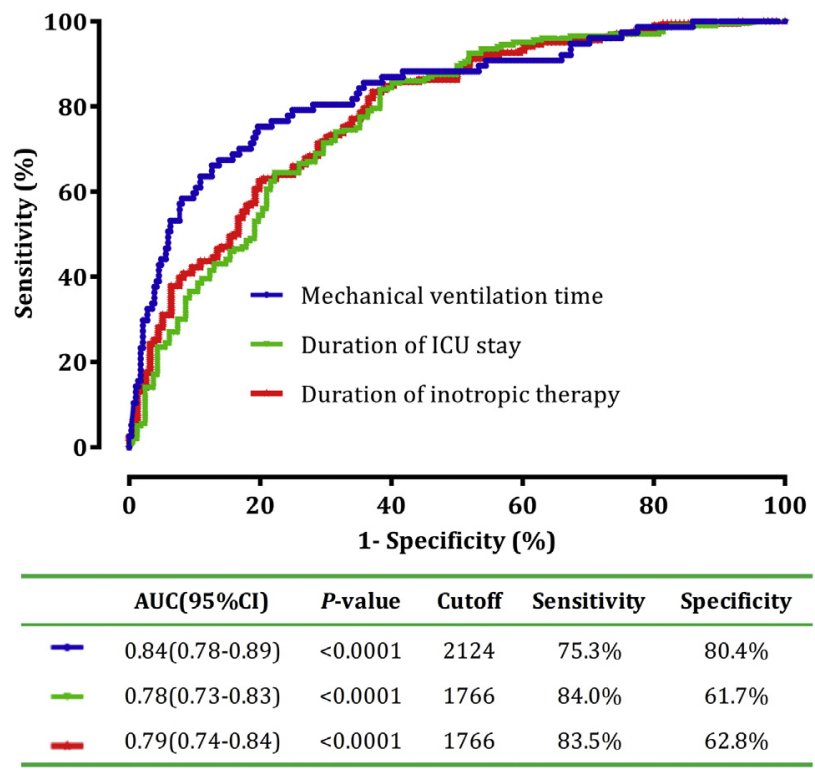

FIGURE 2. Receiver operating characteristic curve for N-terminal pro-brain natriuretic peptide level at 1 hour after congenital heart disease surgery predicting the need for mechanical ventilation beyond 48 hours, intensive care unit $(I C U)$ stay and duration of inotropic therapy beyond 3 days. AUC, Area under the curve; $C I$, confidence interval.

from the analysis if they had evidence of impaired renal function before surgery. Moreover, acute kidney injury (AKI) (defined mainly based on the urine output for early identification) was recorded in 15 cases. Subgroup

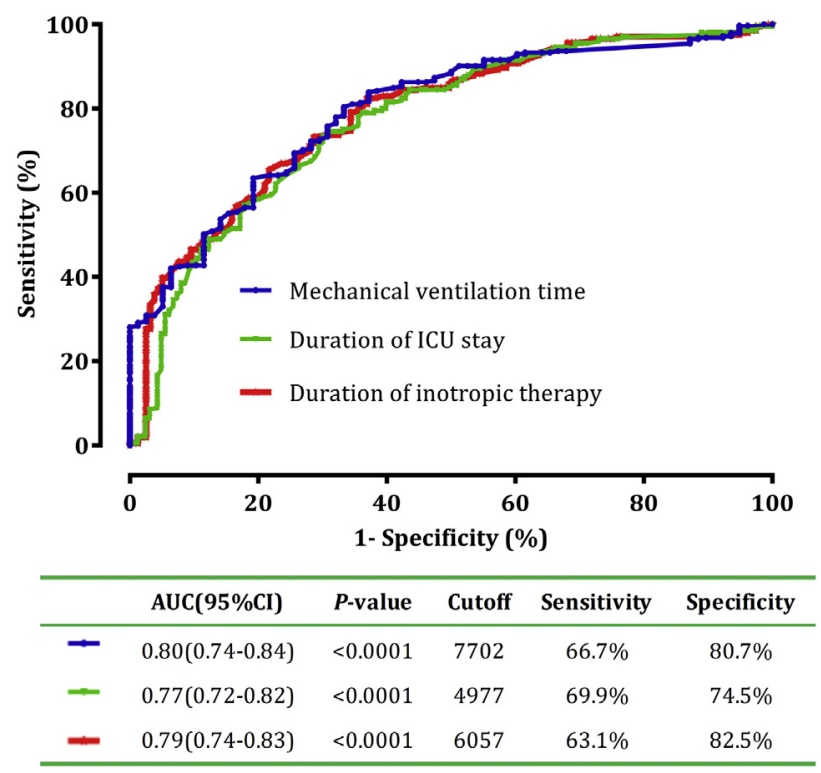

FIGURE 3. Receiver operating characteristic curve for N-terminal pro-brain natriuretic peptide level at 12 hours after congenital heart disease surgery predicting the need for mechanical ventilation beyond 48 hours, intensive care unit $(I C U)$ stay and duration of inotropic therapy beyond 3 days. AUC, Area under the curve; $C I$, confidence interval. 


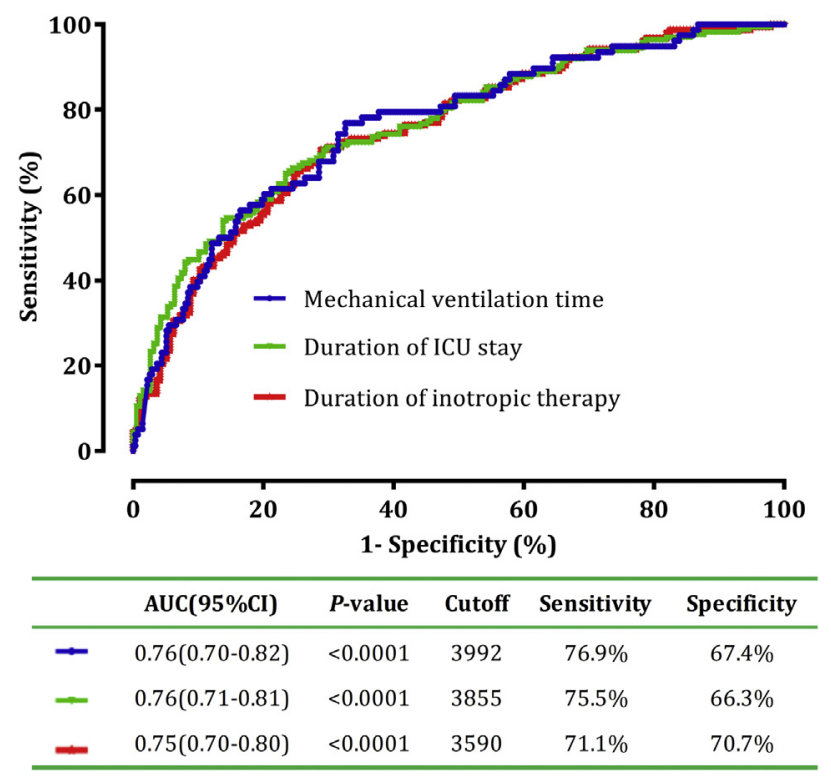

FIGURE 4. Receiver operating characteristic curve for N-terminal pro-brain natriuretic peptide level at 36 hours after congenital heart disease surgery predicting the need for mechanical ventilation beyond 48 hours, intensive care unit $(I C U)$ stay and duration of inotropic therapy beyond 3 days. $A U C$, Area under the curve; $C I$, confidence interval.

analysis showed no significant difference of NT-proBNP levels before and after surgery in patients with and without AKI. This may be related to our timely intervention to the potential AKI patients using peritoneal dialysis.

\section{Limitations}

There are several limitations of the present study that may provide further extension of the research. First, we did not use Doppler imaging for the assessment of ventricular systolic and diastolic function, which may add further prognostic information. Compared with the RACHS-1 scoring system, the Society of Thoracic Surgery-European Association for Cardio-Thoracic Surgery (STAT) for surgical complexity is a more widely accepted risk score in the current era. STAT was not routinely used in pediatric cardiac surgery in our center until now. We cannot adjust STAT as a confounder in the multivariable regression models. However, one recent study ${ }^{26}$ comparing stratification of complexity models (RACHS-1, Aristotle basic score, and STAT) in patients younger than 18 years with CHD, showed that 3 models are with similar discriminatory capacity for hospital mortality. Compared with comprehensive use of both RACHS-1 model and STAT model, the RACHS-1 single model used in our center has some limitations. Obviously, there was also certain rationality based on the results of the comparison of the 2 models. Obviously, we will try to introduce the STAT system in our clinical setting to keep with modern clinical practices. Second, prognostic cutoff points from the ROC analyses are specific for the mentioned population of children without impaired renal function before surgery. The results are specific and can be recommended for use in homogeneous populations. Finally, our study was also limited by the sample size and was not powered to perform subgroup analyses to evaluate the effect of age (eg, neonates), type of CHD, and kinds of reconstruction performed. There is insufficient power to draw definitive conclusions in these subgroups.

\section{CONCLUSIONS}

In conclusion, perioperative NT-proBNP levels in the children undergoing CHD surgery, particularly levels measured 1 hour after surgery, provide stronger prognostic information and might be a more early, accurate, and sensitive predictor of prolonged ventilation, ICU stay, and inotropic support duration. Further studies are warranted to confirm if the routine NT-proBNP monitoring should be performed during postoperative management to identify individuals at high risk of adverse events who might benefit from alternative treatment strategies.

\section{Conflict of Interest Statement}

Authors have nothing to disclose with regard to commercial support.

The authors thank the doctors and nurses at the Department of Heart Center, Guangzhou Women and Children's Medical Center, in particular Xinxin Chen, MD, and his team of surgeons. We thank Ramit Kumar Gupta, MD, for assisting with the English language and preparing the manuscript, and Dr Taishan Zeng from the School of Mathematical Sciences, South China Normal University, for his statistical support, particularly for the joint model using.

\section{References}

1. Yancy CW, Jessup M, Bozkurt B, Butler J, Casey DE Jr, Drazner MH, et al. 2013 ACCF/AHA guideline for the management of heart failure: a report of the American College of Cardiology Foundation/American Heart Association Task Force on Pratice Guidelines. J Am Coll Cardiol. 2013;62:e147-239.

2. Hsu JH, Keller RL, Chikovani O, Cheng H, Hollander SA, Karl TR, et al. B-type natriuretic peptide levels predict outcome after neonatal cardiac surgery. $J$ Thorac Cardiovasc Surg. 2007;134:939-45.

3. Niedner MF, Foley JL, Riffenburgh RH, Bichell DP, Peterson BM, Rodarte A. Btype natriuretic peptide: perioperative patterns in congenital heart disease. Congenit Heart Dis. 2010;5:243-55.

4. Nahum E, Pollak U, Dagan O, Amir G, Frenkel G, Birk E. Predictive value of Btype natriuretic peptide level on the postoperative course of infants with congenital heart disease. Isr Med Assoc J. 2013;15:216-20.

5. Cantinotti M, Giordano R, Scalese M, Molinaro S, Della Pina F, Storti S, et al Prognostic role of BNP in children undergoing surgery for congenital heart disease: analysis of prediction models incorporating standard risk factors. Clin Chem Lab Med. 2015;53:1839-46.

6. Cantinotti M, Iervasi G, Clerico A. B-type natriuretic peptide in children undergoing pediatric cardiac surgery: just a marker of disease severity strongly related to age or much more? J Thorac Cardiovasc Surg. 2014;147:541.

7. Yeo KT, Dumont KE, Brough T. Elecsys NT-ProBNP and BNP assays: are there analytically and clinically relevant differences? J Card Fail. 2005;11:S84-8.

8. Booth RA, Hill SA, Don-Wauchope A, Santaguida PL, Oremus M, McKelvie R, et al. Performance of BNP and NT-proBNP for diagnosis of heart failure in primary care patients: a systematic review. Heart Fail Rev. 2014;19:439-51. 
9. Cantinotti M, Law Y, Vittorini S, Crocetti M, Marco M, Murzi B, et al. The potential and limitations of plasma BNP measurement in the diagnosis, prognosis, and management of children with heart failure due to congenital cardiac disease: an update. Heart Fail Rev. 2014;19:727-42.

10. Mazurek B, Szydłowski L, Giec-Fuglewicz G, Markiewicz-Łoskot G. N-terminal prohormone brain natriuretic peptide-proBNP levels in ventricular arrhythmias in children. Clin Cardiol. 2009;32:690-4.

11. Koch A, Zink S, Dittrich S. Plasma levels of B-type natriuretic peptide in children and adolescents with high degree atrioventricular block. Int J Cardiol. 2009;134:429-30.

12. Gölbaşý Z, Uçar O, Yüksel AG, Gülel O, Aydoğdu S, Ulusoy V. Plasma brain natriuretic peptide levels in patients with rheumatic heart disease. Eur J Heart Fail. 2004;6:757-60.

13. Chen H, Huang Y, Zhang N. Joint modeling of a linear mixed effects model for self-esteem from mean ages 13 to 22 and a generalized linear model for anxiety disorder at mean age 33. J Med Stat Inform. 2015;3:1.

14. Lunn DJ, Thomas A, Best N, Spiegelhalter D. WinBUGS-a Bayesian modeling framework: concepts, structure, an extensibility. Statistics and Computing. 2000; 10:325-37.

15. Pérez-Piaya M, Abarca E, Soler V, Coca A, Cruz M, Villagrá F, et al. Levels of Nterminal-pro-brain natriuretic peptide in congenital heart disease surgery and its value as a predictive biomarker. Interact Cardiovasc Thorac Surg. 2011;12:461-6.

16. Cantinotti M, Clerico A, Iervasi G. Age- and disease-related variations in B-type natriuretic peptide response after pediatric cardiac surgery. J Thorac Cardiovasc Surg. 2013;145:1415-6.

17. Cannesson M, Bionda C, Gostoli B, Raisky O, di Filippo S, Bompard D, et al. Time course and prognostic value of plasma B-type natriuretic peptide concentration in neonates undergoingthe arterial switch operation. Anesth Analg. 2007; 104:1059-65. tables of contents.

18. Kubánek M, Goode KM, Lánská V, Clark AL, Cleland JG. The prognostic value of repeated measurement of $\mathrm{N}$-terminal pro-B-type natriuretic peptide in patients with chronic heart failure due to left ventricular systolic dysfunction. Eur J Heart Fail. 2009;11:367-77.
19. Cantinotti M, Walters HL, Crocetti M. BNP in children with congenital cardiac disease: is there now sufficient evidence for its routine use? Cardiol Young. 2015; 25:424-37.

20. Shih CY, Sapru A, Oishi P, Azakie A, Karl TR, Harmon C, et al. Alterations in plasma B-type natriuretic peptide levels after repair of congenital heart defects: a potential perioperative marker. J Thorac Cardiovasc Surg. 2009; 131:632-8

21. Hoffman TM, Wernovsky G, Atz AM, Kulik TJ, Nelson DP, Chang AC, et al. Efficacy and safety of milrinone in preventing low cardiac output syndrome in infants and children after corrective surgery for congenital heart disease. Circulation. 2003;107:996-1002.

22. Ricci Z, Garisto C, Morelli S, di Chiara L, Ronco C, Picardo S. Brain natriuretic peptide is removed by continuous veno-venous hemofiltration in pediatric patients. Interact Cardiovasc Thorac Surg. 2009;9:33-6.

23. Walsh R, Boyer C, LaCorte J, Parnell V, Sison C, Chowdhury D, et al. N-terminal B-type natriuretic peptide levels in pediatrics with congestive heart failure undergoing cardiac surgery. J Thorac Cardiovasc Surg. 2008;135:98-105.

24. Yoshitomi R, Nakayama M, Sakoh T, Fukui A, Shikuwa Y, Tominaga M, et al. Plasma B-type natriuretic peptide concentration is independently associated with kidney function decline in Japanese patients with chronic kidney disease. J Hypertens. 2016;34:753-61.

25. Cantinotti M, Storti S, Lorenzoni V, Arcieri L, Moschetti R, Murzi B, et al. The combined use of neutrophil gelatinase-associated lipocalin and brain natriuretic peptide improves risk stratification in pediatric cardiac surgery. Clin Chem Lab Med. 2012;50:2009-17.

26. Kogon B, Oster M. Assessing surgical risk for adults with congenital heart disease: are pediatric scoring systems appropriate? J Thorac Cardiovasc Surg. 2014;147:666-71.

Key Words: N-terminal pro-brain natriuretic peptide, congenital heart disease, surgery, predictor, children

Readers who found these articles interesting may also like to read the following papers found in recent and future issues of our sister publications, Seminars in Thoracic and Cardiovascular Surgery and Operative Techniques in Thoracic and Cardiovascular Surgery!

\section{Congenital: Perioperative Management}

ORIGINAL SUBMISSION: The Effect of Noncardiac and Genetic Abnormalities on Outcomes Following Neonatal Congenital Heart Surgery. Bahaaldin Alsoufi. Semin Thoracic Surg 2016: 105 -117.

Editorial Commentary: God is in the Detail: The Effect of Noncardiac and Genetic Abnormalities on Outcomes Following Neonatal Congenital Heart Surgery. Scott M. Bradley. Semin Thoracic Surg 2016: 118-119.

ORIGINAL SUBMISSION: Validation of a Simple Score to Determine Risk of Hospital Mortality After the Norwood Procedure. Shahryar M. Chowdhury. Semin Thoracic Surg 2016: 425-433.

Editorial Commentary: The Pearls and Perils of Settling Scores in Public. Edward Buratto. Semin Thoracic Surg 2016: 434-435. 